\title{
Local scour around two subsea pipelines in an oscillatory flow
}

\author{
M. Zhao \\ School of Computing, Engineering and Mathematics, Western Sydney University, Penrith 2751, NSW, \\ Australia \\ M. Liu \& L. Lu \\ State Key Laboratory of Coastal and Offshore Engineering, Dalian University of Technology, Dalian 116024, \\ China \\ L. Cheng, H. An \& S. Draper \\ School of Civil, Environmental and Mining Engineering, University of Western Australia, Australia
}

\begin{abstract}
In offshore engineering, wave generated flows are generally modelled as oscillatory flows when flow around small scale cylindrical structures are considered. The understanding of local scour around subsea pipelines under waves is important to ensure the stability of pipelines. In this study, local scour around two identical pipelines in a tandem arrangement in an oscillatory flow is investigated numerically. The flow around the pipelines is simulated by the Reynolds-averaged Navier-Stokes (RANS) equations and the local scour is predicted by solving the conservation equation of the sediment mass. The numerical model is firstly validated against experimental data. Then, the effects of the gap between the two pipelines and the $\mathrm{KC}$ number on the scour depth below the pipelines are examined over a wide parameter space.
\end{abstract}

\section{INTRODUCTION}

Local scour around subsea pipelines under steady current and wave conditions is the main factor that affects pipeline stability. It may lead to suspension and the vibration of the pipeline. Scour below subsea pipelines under steady current has been studied extensively in the past decades and the mechanisms of the scour have been understood (Sumer et al., 1988; Chiew, 1990; Sumer \& Fredsøe, 2002; Dey \& Singh, 2007). It was found that the scour process below a pipeline in a steady current mainly includes two stages: tunnel scour in the early stage and the leewake scour in the late stage. Numerical models have also been developed to predict local scour around subsea pipelines under steady currents. Early developed numerical models are efficient in predicting the equilibrium scour depth (Li \& Cheng; Lu et al., 2005) but not able to predict the scour process. Recent numerical models can predict the time-scale of the scour by solving the sediment transport equation and predicting the process of the scour from the onset to the equilibrium stage (Brørs, 1999; Liang \& Cheng, 2005; Zhao \& Cheng, 2008). Studies about local scour have also been extended to the threedimensional scour progressing along the pipeline span, and some empirical formulae have been developed for calculating the spanwise progressing speed of scour (Cheng et al., 2009, 2014).

Compared with the studies of local scour in steady current condition, studies on local scour under waves have been relatively rare. Sumer \& Fredsøe (1990) conducted an experimental study of scour below pipelines under waves and found that the scour depth in the live bed scour condition is mainly governed by the $\mathrm{KC}$ number, while the effect of the Shields parameter on the scour depth is weak. The Shields parameter is defined as

$\theta=u_{f}^{2} /\left[g(s-1) d_{50}\right]$

where $u_{f}=\sqrt{\tau / \rho}$ is the friction velocity and $\tau$ and $\rho$ are the shear stress on the seabed and the fluid density, respectively, $g$ is the gravitational acceleration, $d_{50}$ is the median sediment particle diameter and $s$ is the specific gravity of the sediment. The KC number is defined as

$K C=U_{\mathrm{m}} T / D$

where $U_{\mathrm{m}}, T$ and $D$ are the amplitude of the oscillatory flow velocity, period of the waves and the diameter of the pipeline, respectively.

When scour below pipelines under waves is simulated, the fluid motion due to waves is generally modelled as an oscillatory flow. Some numerical models have been developed successfully to predict local scour under oscillatory flow conditions. Liang \& Cheng (2005) developed a numerical model to predict local scour below a subsea pipeline under waves, where the scour was predicted by the periodaveraged sediment transport rate. Fuhrman et al. (2014) studied scour and self-burial of a subsea pipeline under waves through numerical simulations. 
Two pipelines are sometimes laid in parallel due to technical and economical consideration. The effect of the spacing between two parallel pipelines on local scour in a steady current has been studied by Zhao et al. (2015). In this study, scour below two parallel pipelines under waves will be studied numerically. The numerical model used in this study is the same as that proposed by Zhao et al. (2015). Simulations are performed for gap ratios of $0.5,1$ and 2 and $\mathrm{KC}$ numbers ranging from 5 to 20 . The gap ratio is defined as the ratio of the gap between the two cylinders $(G)$ to the cylinder diameter $(D)$. The effects of the gap ratio and the $\mathrm{KC}$ number on the scour process and the scour depth are discussed.

\section{NUMERICAL METHOD}

\subsection{Governing equations and boundary conditions}

The wave induced motion of the fluid is modelled by a sinusoidal oscillating flow. The numerical method used in this study is the same as the one used in Zhao et al. (2015). In this section the numerical method is described briefly and the detailed numerical method can be found in Zhao et al. (2015). The governing equations for simulating the oscillatory flow around the subsea pipelines are the ReynoldsAveraged Navier-Stokes equations closed by the SST (shear stress transport) $k$ - $\omega$ turbulence equation (Menter, 1994). The finite element method developed by Zhao et al. (2007) is used to solve the RANS and $k-\omega$ equations. A $100 D$ long and $20 D$ high computational domain is used and the two pipelines are located at the centre of the computational domain. Figure 1 shows an example of the computational mesh near the pipelines. The whole computational domain is divided into 13,628 4-node quadrilateral bi-linear finite elements. Initially, a very small gap of $0.1 D$ is preset below each pipeline to avoid totally re-meshing. The initial, very dense mesh between the cylinders and the seabed ensure that good mesh quality is retained after the scour reaches its equilibrium stage, as shown in Figure 1 (b).

At the left and right boundary the velocity is given as

$u(t)=U_{\mathrm{m}} \sin (2 \pi t / T)$

and the pressure is given as

$p(t)=\rho x(2 \pi / T) U_{\mathrm{m}} \cos (2 \pi t / T)$

where $x$ is the horizontal coordinate, whose origin is and at the centre between the two pipelines on the seabed. On the left and right boundary, the turbulent energy $k$ is zero and specific dissipation of turbulent kinetic energy $\omega$ is given to be a very small value. The numerical tests demonstrated that the flow has been fully developed at the $50 D$ long centre of the computational domain. On the cylinder surface, the fluid velocity is zero, the turbulent energy $k$ is zero and the specific dissipation rate of the turbulence $\omega=6 v /\left(0.075 \Delta_{1}^{2}\right)$, where $v$ and $\Delta_{1}$ are the kinematic viscosity of the fluid and the distance between the first layer of finite element nodes and the wall, respectively.

\subsection{Scour model}

In the sediment transport model, both the bedload and the suspended load are considered. The suspended sediment concentration is calculated by solving the convection-diffusion equation of the concentration of the suspended sediment, which is solved by the Petrov-Galerkin Finite Element Method (PGFEM). The boundary condition of the sediment concentration at the reference level $z_{\mathrm{a}}$ above the seabed $\left(z_{\mathrm{a}}=2.5 d_{50}\right)$ is given based on the formula by Zyserman \& Fredsøe (1990) as:

$$
c_{\mathrm{a}}=\left[0.331\left(\theta-\theta_{\text {sus }}\right)^{1.75} /\left[1+0.72\left(\theta-\theta_{\text {sus }}\right)^{1.75}\right]\right.
$$

where $\theta_{\text {sus }}$ is the critical Shields parameter for the suspension of the sediment, which is 0.045 for loose inviscid sand. The suspended load is calculated by integrating the suspended sediment flux over the water depth, i.e.

$q_{s}=\int_{z_{\mathrm{a}}}^{h} u c \mathrm{~d} z$

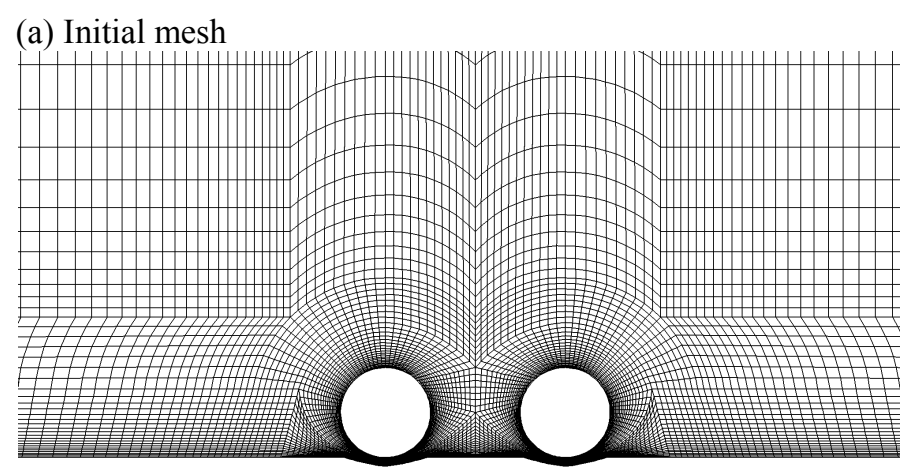

(b) After scour

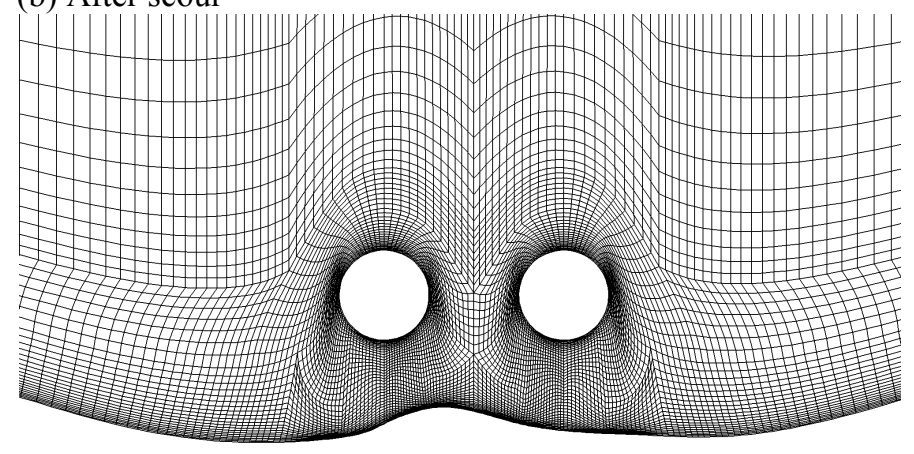

Figure 1. The computational mesh near the two pipelines for $G / D=1$

The bedload is calculated based on the empirical formula by Engelund \& Fredsøe (1976)

$q_{b}=\frac{1}{6} \pi d_{50}^{3} d P_{E F} U_{b}$ 
where $P_{E F}=\left\{1+\left[(1 / 6) \pi \mu_{d} /\left(\theta-\theta_{c}\right)\right]^{4}\right\}^{1 / 4}$ is the percentage of particles in motion in the surface layer of the bed, $U_{b}=a u_{f}\left(1-0.7 \sqrt{\theta / \theta_{c}}\right)$ is the mean transport velocity of a particle moving along the bed, $a=10$ is an empirical constant, $\theta_{c}$ the threshold Shields parameter and $\mu_{d}$ is the dynamic friction coefficient, taken as 0.51 . For sand on a sloping bed, the threshold Shields parameter is modified as (Allen, 1982)

$\theta_{c}=\theta_{c 0}(\cos \alpha+\sin \alpha / \tan \phi)$

where $\theta_{\mathrm{c} 0}$ is the threshold Shields parameter on a flat bed, $\alpha$ is the bed slope angle and $\phi$ is the angle of repose of the sediments, which is set to be $\tan \phi=0.61$. The critical Shields parameter for a flat seabed is calculated based on the empirical formula by Soulsby (1997)

$$
\theta_{c 0}=\frac{0.30}{1+1.2 D_{*}}+0.055\left[1-\exp \left(-0.020 D_{*}\right)\right]
$$

The following conservation equation of the sediment mass is solved for modelling the bed profile evolution.

$\frac{\partial z_{b}}{\partial t}=-\frac{1}{1-\lambda_{s}} \frac{\partial q}{\partial x}$

where $q=q_{\mathrm{b}}+q_{\mathrm{s}}$ is the total sediment transport rate, $z_{\mathrm{b}}$ is the elevation of the sand bed surface, $\lambda_{\mathrm{s}}$ is the sediment porosity, which is set to 0.4 , respectively.

The inputted uniform flow at the left and right boundaries needs to travel a distance before it develops into a fully developed boundary layer flow. In the numerical simulation, the left and the right two quarters of seabed ( $25 \mathrm{D}$ long on each side) is treated as being rigid $\left(z_{\mathrm{b}}\right.$ does not change). The scour only occurs in the $50 D$ long central part of the domain.

In a number of numerical models for scour below pipelines in steady currents (Brørs, 1999; Liang et al., 2005; Zhao \& Cheng, 2008), the computational time-step for scour simulation is much greater than that for flow simulation in order to speed up the simulation of long duration scour processes. This is equivalent to keeping the scour rate unchanged for a step longer than the computational time-step. Considering that the fluid velocity in an oscillatory flow changes faster than in a steady flow, the scour is not speeded up in this study, i.e., the flow time-step is the same as the scour time-step. This slows down the simulation significantly, but ensures the accuracy of the results.

\section{NUMERICAL RESULTS}

\subsection{Validation of the numerical model}

The numerical model is validated by comparing the numerical results with the experimental data of $\mathrm{Su}-$ mer \& Fredsøe (1990). Two test cases that are used to validate the numerical model are listed in Table 1 .

Figure 2 shows the comparison between the computed and measured seabed profiles for Cases 1 and 2 listed in Table 1. It can be seen that the numerical results agree well with the experimental data. The simulated scour profiles are smoother than the measured, probably because the experiments were conducted under surface waves, while the numerical simulations are conducted in oscillatory flow. The computed maximum scour depths at the pipeline centre agree with the measured data exceptionally. It can be seen in Figure 2 that the extent of the scour becomes wider with increasing $\mathrm{KC}$ number.

Table 1. Experimental parameters in two test cases by Sumer and Fredsøe (1990)

\begin{tabular}{|l|l|l|}
\hline Case & 1 & 2 \\
\hline Pipeline diameter $D(\mathrm{~mm})$ & 50 & 30 \\
\hline Oscillatory flow period $T(\mathrm{~s})$ & 1.43 & 1.22 \\
\hline Fluid velocity amplitude $(\mathrm{m} / \mathrm{s})$ & 0.228 & 0.240 \\
\hline Median particle size $d_{50}(\mathrm{~mm})$ & 0.58 & 0.18 \\
\hline KC number & 7 & 11 \\
\hline
\end{tabular}
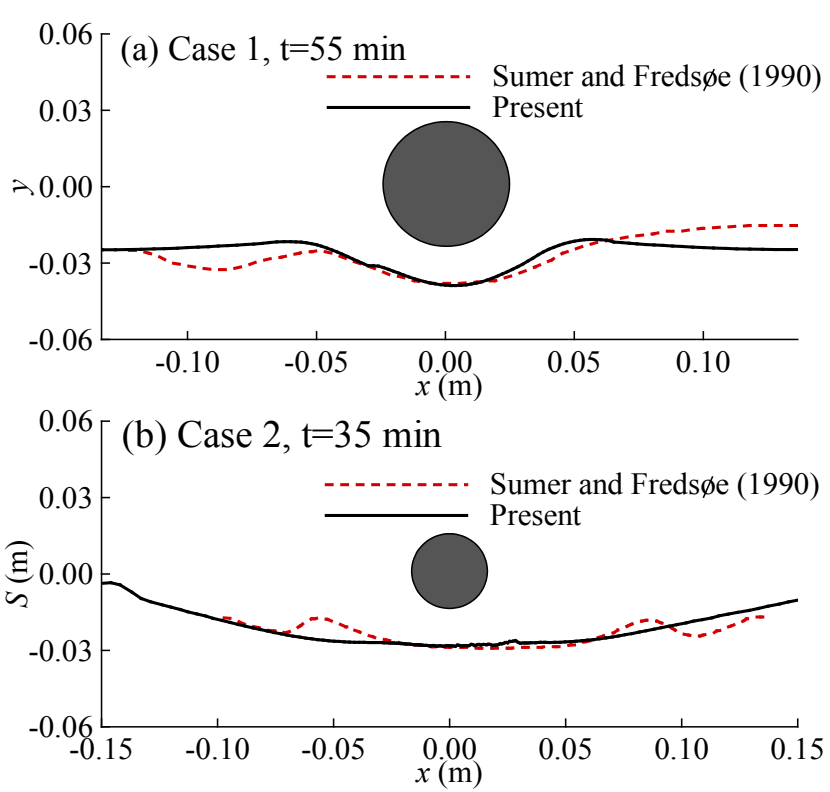

Figure 2. Comparison between the computed and the measured scour profiles 

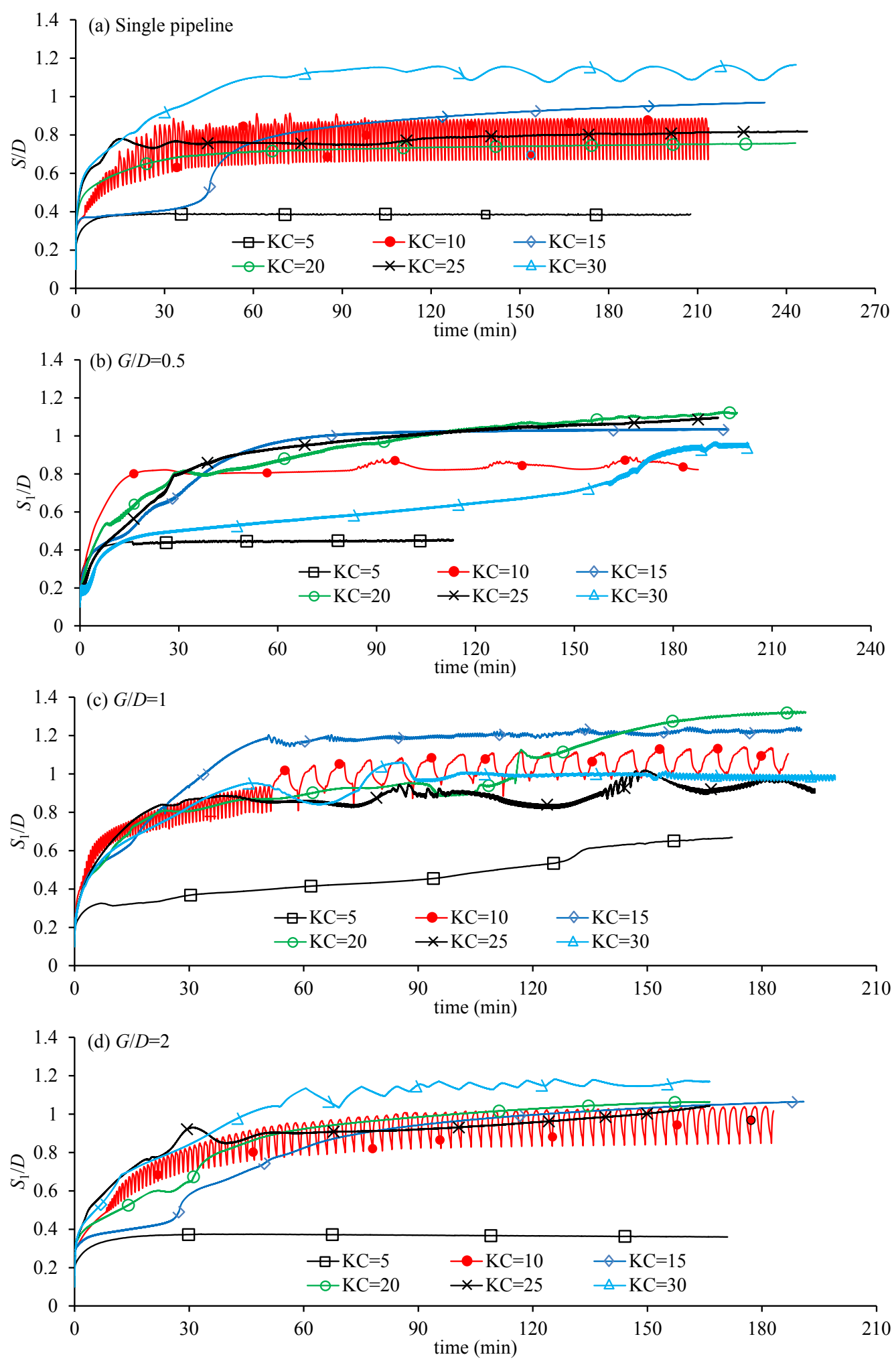

Figure 4. Time histories of the scour depth below left pipeline. The scour depth below the right pipeline is the same as that of the right. 

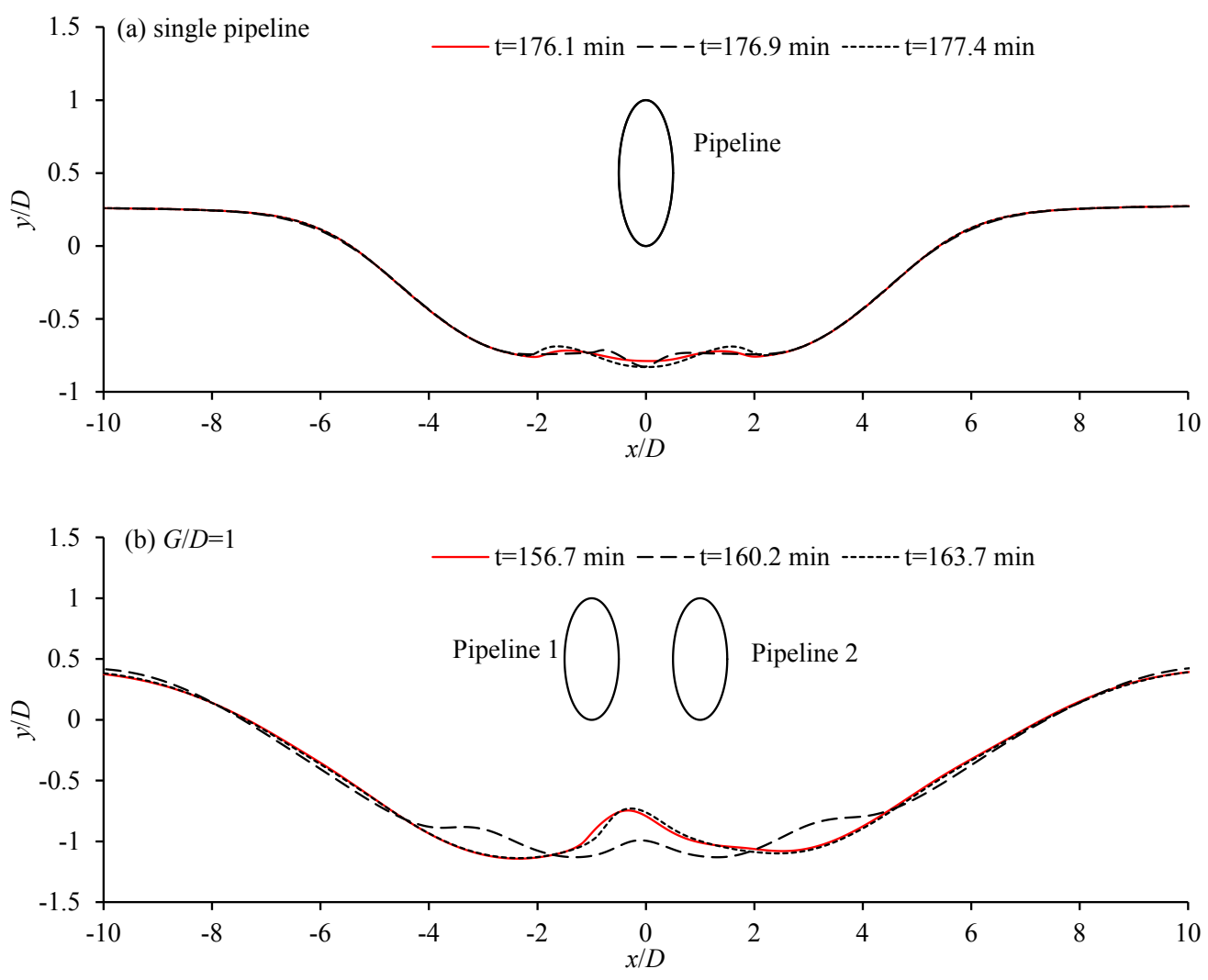

Figure 5. Scour profiles near the pipelines for two cases of a single pipeline and two pipelines with $G / D=1$

\subsection{Scour below two pipelines}

When the scour below two pipelines is simulated, the diameter of the pipeline model is $30 \mathrm{~cm}$ and the sediment particle size and the fluid velocity amplitude are kept constant at $0.18 \mathrm{~mm}$ and $0.3 \mathrm{~m} / \mathrm{s}$, respectively. The $\mathrm{KC}$ number is varied by varying the period of the oscillatory flow velocity. Three gap ratios of $G / D=0.5,1$ and 2 are considered. To see the difference between the scour below a single pipeline and the scour below two pipelines, scour around a single pipeline is also simulated.

Due to the symmetric configuration of the twopipeline system, the scour depths below the two pipelines are found to be the same. Figure 4 shows the time histories of the scour depth below the left pipeline for all the simulated cases. It can be clearly seen that the scour depth for $K C=5$ is the smallest among other $\mathrm{KC}$ numbers for all the cases. In addition, the scour for $K C=5$ reaches equilibrium much faster than those in other $\mathrm{KC}$ numbers, except for the case of $G / D=1$. It is interesting to see that the scour depth below each pipeline centre oscillates with time for $K C=10$ for all the gap ratios. The oscillation periods of the scour depth below each pipeline centre is greater than the oscillatory flow period.

For scour due to waves under live bed conditions, the seabed is dynamic. However, the oscillation of the seabed level with a period lower than the oscillatory flow period has not been reported previously. And this oscillatory period is found to vary with the gap ratio as shown in Figure 4. Not considering $G / D=0.5$, where the oscillation amplitude of the seabed level is very small, the oscillation period for $G / D=1$ is the largest and that for a single cylinder is the smallest. To show how the seabed level below the pipelines oscillates with time, Figure 5 shows the seabed profiles for a single pipeline case and a twopipeline case with $G / D=1$. It is obvious that the seabed surfaces near the pipelines are dynamic. If a time-averaged seabed profile at the latest stage of the scour is obtained, it is generally symmetric with respect to the $x / D=0$ point. Strong oscillation of the seabed level only occurs near the pipelines. The oscillation of the seabed surface far away from the pipelines is not obvious. In this study, small pipeline models are used and the fluid velocity is comparable to the prototype case. It is considered that the nondimensional oscillation amplitude is dependent on the model scale. This needs to be proved by conducting more simulations at large model scales in future studies.

Figure 6 shows the variation of the scour depth at $t=180$ min with the KC number for all the calculated cases. It can be seen that the rate of change of the scour depth after 180 minutes is very small. In the cases where the scour depth oscillates with time, the scour depths shown in Figure 6 are the maximum scour depths. The scour depth increases quickly as the $\mathrm{KC}$ number is increased from 5 to 10 . As $K C>10$, the scour depth does not change significantly with increasing $\mathrm{KC}$ number. The scour depth be- 
low each pipeline is generally found to be increased compared with that of a single pipeline, except that for $K C=30$. The maximum increment appears to occur for $G / D=1$ when the $\mathrm{KC}$ number is in the range of $5 \leq K C \leq 20$. It is shown that the scour below the two pipelines with $G / D=1$ increases by about $75 \%$ compared with that of a single pipeline.

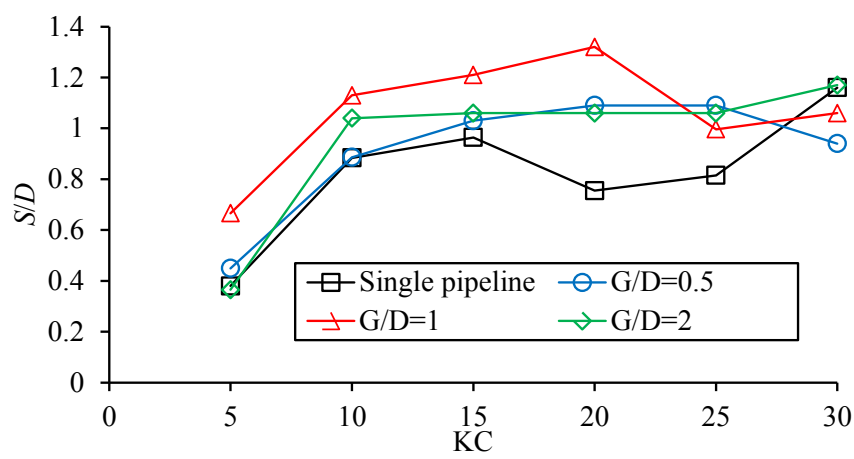

Figure 6. Variation of the equilibrium scour depth with the KC number

\section{CONCLUSIONS}

Scour below two pipelines under wave only condition is simulated numerically. The simulations are conducted for gap ratios of $G / D=0.5,1$ and 2 and $\mathrm{KC}$ numbers ranging from 0 to 30 with an increment of 5. For all the gap ratios considered, the minimum scour depth occurs at $K C=5$. The scour depth below the pipelines are found to oscillate with time at a period greater than the wave period for $K C=10$ and some gap ratios. The oscillation of the scour depth mainly occurs in an area near the pipelines. The maximum amplitude of the seabed level oscillation is about $15 \%$ of the scour depth and it occurs at $G / D=1$. Compared with that of a single cylinder, the maximum increase in the scour depth below the pipelines occurs at $K C=20$. For $G / D=1$ and $K C=20$, the equilibrium scour depth below each pipeline is about $75 \%$ greater than that below a single pipeline.

\section{REFERENCES}

Brørs, B. (1999). Numerical modelling of flow and scour at pipelines. Journal of Hydraulics Engineering 125 (5), 511522.

Cheng, L., Yeow, K., Zang, Z. \& Teng, B. (2009). Threedimensional scour below pipelines in steady currents. Coastal Engineering 56 (5-6), 577 - 590.

Cheng, L. Yeow, K., Zang, Z. \& Li, F. (2014). 3D scour below pipelines under waves and combined waves and currents. Coastal Engineering 83, 137-149.

Chiew, Y.M. (1990). Mechanics of local scour around submarine pipelines. Journal of Hydraulic Engineering 116 (4), 515-529.
Dey, S. \& Singh, N.P. (2007). Clear water scour depth below underwater pipelines. Journal of Hydro-environment Research 1, 157-162.

Fuhrman, D.R., Baykal, C., Sumer, B.M., Jacobsen, N.G. \& Fredsøe, J. (2014). Numerical simulation of wave-induced scour and backfilling processes beneath submarine pipelines. Coastal Engineering 94, 10-22.

Li, F., \& Cheng, L. (1999). A numerical model for local scour under offshore pipelines. Journal of Hydraulic Engineering 125 (4), 400-406.

Liang, D. \& Cheng, L. (2005). Numerical model for waveinduced scour below a submarine pipeline. Journal of $\mathrm{Wa}$ terway, Port, Coastal and Ocean Engineering 131 (5), 193202.

Liang, D., Cheng, L., \& Li, F. (2005). Numerical modeling of flow and scour below a pipeline in currents. Part II: Scour simulation. Coastal Engineering. 52 (1), 43-62.

Lu, L., Li, Y., \& Qin, J. (2005). Numerical simulation of the equilibrium profile of local scour around submarine pipelines based on renormalized group turbulence model. Ocean Engineering 32 (17-18), 2007-2019.

Menter, F. R. (1994). Two-equation eddy-viscosity turbulence models for engineering applications. AIAA Journal, 32 (8), 1598-1605.

Soulsby, R. (1997). Dynamics of Marine Sands, Tomas Telford, London.

Sumer, B. M., Jensen, H. R. \& Fredsøe, J. (1988). Effect of leewake on scour below pipelines in current. Journal of $\mathrm{Wa}$ terway, Port, Coastal and Ocean Engineering, 114(5), 599-614.

Sumer, B. M. \& Fredsøe, J. (1990). Scour below pipelines in waves. Journal of Waterway, Port, Coastal and Ocean Engineering 116 (3), 307-323.

Sumer, B. M. \& Fredsøe, J. (2002). The mechanics of scour in the marine environment, World Scientific, Singapore.

Zhao, M. \& Cheng, L. (2008). Numerical modelling of local scour below a piggyback pipeline in currents, Journal of Hydraulic Engineering 134 (10), 1452-1463.

Zhao, M., Cheng, L., Teng, B. \& Dong, G. (2007). Hydrodynamic forces on dual cylinders of different diameters in steady flow. Journal of fluids and structures, 23, 59-83.

Zhao, M., Vaidya, S., Zhang, Q. \& Cheng, L. (2015). Local scour around two pipelines in tandem in steady current. Coastal Engineering 98, 1-15.

Zyserman, J. \& Fredsøe, J. (1990). Data analysis of bed concentration of suspended sediment. Journal of Hydraulic Engineering 120 (9), 1021-1042. 